\title{
Circulation Control and Its Application to Extreme Short Take-Off and Landing Vehicles
}

\author{
Julianna B. de la Montanya* and David D. Marshall ${ }^{\dagger}$ \\ California Polytechnic State University, San Luis Obispo, California 93407
}

\begin{abstract}
Circulation Control is a high-lift method discovered in 1935 when Henry Coanda accidentally stumbled upon the technology. Research was conducted in the 1970's and 1980's to develop this technique, but the idea fell out of vogue until recently. Energy is introduced into the flow field by means of a jet ejected tangentially from a slot located near the trailing edge of the airfoil; thus changing the effective chamber of the airfoil and increasing lift. Extreme Short Take-Off and Landing (ESTOL) vehicles can use this technology to alleviate today's congested airports by reutilizing the small runways that are currently unexploited due to the recent trend of bigger aircraft. By examining the angle-of-attack, flap deflection angle, and jet blowing coefficient, a design space was analyzed for lift and drag revealing three-dimensional lift coefficients up to 3.5. After collecting the data, balanced field length and landing distances were calculated. These results revealed that the shortest balanced field length of 2,400 feet would be for a flap deflection angle of thirty degrees and a blowing coefficient equal to 0.35 . Similarly, the shortest landing distance was calculated to be 2,000 feet for a flap deflection angle of ninety degrees and a blowing coefficient of 0.34 . Both of these values fall within the NASA defined mission requirements ${ }^{46}$ for an ESTOL aircraft to have a balanced field length and landing distance between 2,000 to 3,000 feet, proving Circulation Control to be an extremely viable resource for ESTOL technology.
\end{abstract}

\section{Nomenclature}

$\begin{array}{ll}\mathrm{A} & =\text { area } \\ \mathrm{a} & =\text { speed of sound } \\ \text { AoA } & =\text { Angle-of-Attack } \\ c & =\text { chord length } \\ C_{D} & =\text { drag coefficient } \\ C_{L} & =\text { lift coefficient } \\ C_{P} & =\text { pressure coefficient } \\ C_{\mu} & =\text { blowing coefficient } \\ h & =\text { jet slot height } \\ \mathrm{L} / \mathrm{D} & =\text { lift to drag ratio } \\ \mathrm{M} & =\text { Mach number } \\ \dot{m} & =\text { mass flow rate } \\ R & =\text { universal gas constant } \\ S_{r e f} & =\text { wing reference area }\end{array}$

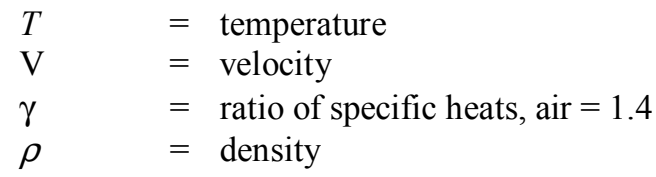

Subscripts

$\begin{array}{ll}\text { app } & =\text { approach } \\ \text { cruise } & =\text { cruise } \\ \text { jet } & =\text { jet ejection slot } \\ \text { ref } & =\text { reference } \\ \text { study } & =\text { related to this study } \\ \text { TO } & =\text { take-off } \\ \infty & =\text { freestream }\end{array}$

\footnotetext{
* Former Graduate Student, Aerospace Engineering, California Polytechnic State University, San Luis Obispo, CA 93407-0352, (Aerospace Engineer, Lockheed Martin Aeronautics Company, Palmdale, CA, 93551), Member.

† Assistant Professor, Aerospace Engineering, California Polytechnic State University, San Luis Obispo, CA 93407-0352, Member.
} 


\section{Introduction}

\section{A. Circulation Control}

$\mathrm{C}$ IRCULATION Control (CC) is an active flow control system designed to produce increased lift over the traditional systems currently in use. Energy is introduced into the flow field by means of a jet ejected tangentially from a slot located near the trailing edge of the airfoil. The jet flow follows a curved surface known as a Coanda surface to deflect the air and create improved lift. When the jet sheet velocity is greater than that of the free stream flow, the jet remains attached to the Coanda surface because of the balance between the sub-ambient pressure within the jet flow and the centrifugal force felt on the curved surface. As jet

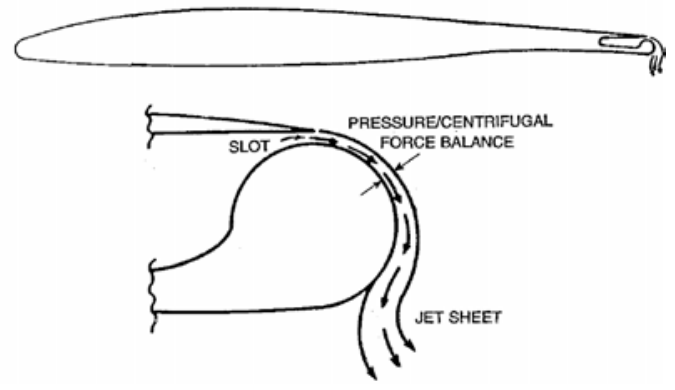
Figure 1. Basic
Circulation
Configuration with Trailing Edge Detail ${ }^{1}$ velocity increases, the stagnation point moves forward on the lower trialing edge inducing an effective camber, thereby increasing circulation around the wing and lift.

Research has been conducted on CC technology from the time that Henri Coanda accidentally stumbled upon what was to be known as the Coanda effect in 1935. He was trying to deflect the exhaust of an engine but instead entrained the air and demolished the aircraft ${ }^{4}$. These research areas include CFD simulations and experimental research including wind tunnel testing, full scale static testing, and a limited number of flight testing.

\section{B. Extreme Short Take-Off and Landing (ESTOL) Vehicles}

Airport activity has increased considerably over the last few years. As a result airports have become extremely congested and have undergone many flight delays and cancellations. One way to alleviate this growing problem is to utilize the runways, airport ground, and infrastructure that are already in existence at major airports, but are too small for large aircraft all while maintaining current air traffic patterns. By making use of the smaller runways for shorter flights ESTOL vehicles will greatly improve current airport problems.

ESTOL vehicles are being extensively investigated at the National Aeronautics and Space Administration (NASA) and other independent companies. To date, the NASA ESTOL vehicle sector has set forth goals for a stateof-the-art 100 passenger airliner to be operational by the year 2022: a take-off and landing distance of less than

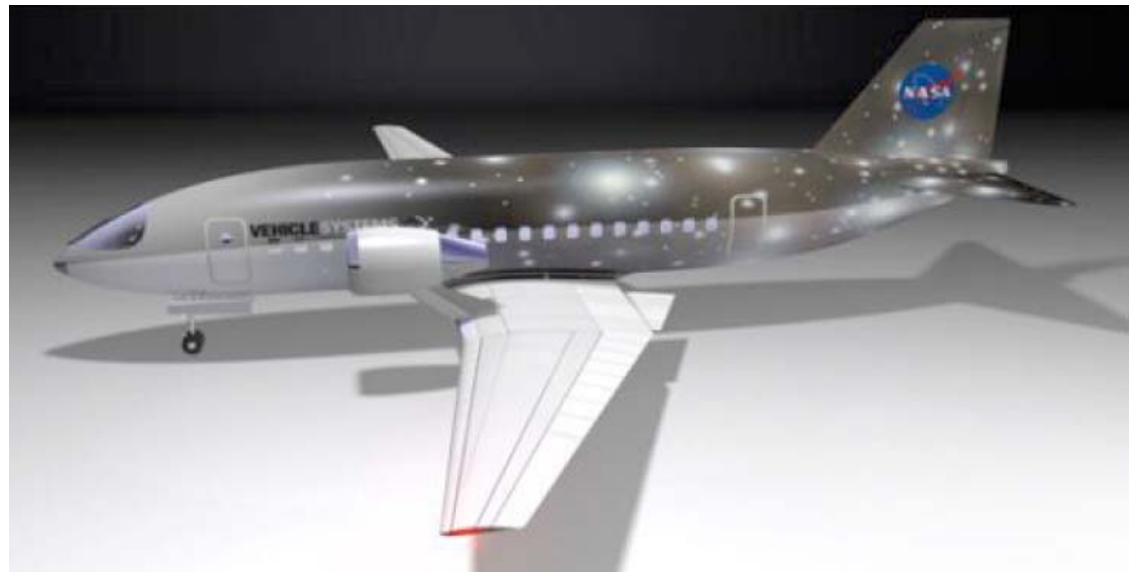

Figure 2. NASA Extreme Short Take-Off and Landing Vehicle Concept ${ }^{2}$ 2,000 feet, a cruise Mach number $\geq 0.8$, a 1,400 to 2,000 mile range capability, noise containment within an airport footprint, and low speed maneuverability. ${ }^{46}$

In the past these goals have been individually achieved but never has one vehicle been able to achieve all objectives. The cruise Mach number requirement of $\geq 0.8$ will enable ESTOL vehicles to fly at similar speeds as conventional jet airliners therefore giving riders a smoother transition to a new class of air vehicle. The take-off and landing requirement is what will enable ESTOL vehicles to be more widely accepted into existing airports since new airport infrastructure will not need to be built; and by combining the low speed maneuverability with the short take-off and landing, ESTOL vehicles will be capable of fitting into a wide variety of airport specific procedures. 


\section{Using Circulation Control for ESTOL}

The big picture solution for implementing ESTOL vehicles is to achieve shorter runway distances. In order to do this the aircraft in question needs to be able to achieve high lift coefficients. Circulation control technology seems an obvious advantage for high-lift capability. Preliminary studies have shown extensive improvements over traditional high-lift devices. Because of this, the technology lends itself extremely well to ESTOL vehicles and should be able to effectively shorten runway distances while decreasing approach and departure speeds.

\section{Circulation Control Wing Geometry}

The wing was designed based on 2-D airfoil information, a typical wing planform for a 100 passenger transport and typical flap span distribution in order to demonstrate how circulation control applies to ESTOL vehicles.

\section{A. Two-Dimensional Airfoil}

The airfoil for the circulation control wing is based on the Georgia Tech Research Institute's Dual Radius Circulation Control airfoil ${ }^{14}$. This airfoil was chosen because out of all of the airfoil shapes that have been tested the dual radius is the only mechanically simple system that allows for both low cruise drag and a large Coanda flap surface for high lift during takeoff and landing. The actual airfoil coordinates are proprietary, so by comparing a picture of the airfoil ${ }^{18}$ to supercritical airfoil shapes the baseline airfoil was chosen to be the NASA SC(2)-0414.

The supercritical contour was chosen to reduce the likelihood of stall since a leading edge device is omitted for this study. The dual radius flap was then constructed within the SC(2)-0414 existing shape. The jet slot location is at an $\mathrm{x} / \mathrm{c}$ of $89.86 \%$, and the slot height to chord ratio $(\mathrm{h} / \mathrm{c})$ is 0.0016 . The slot height to chord ratio is below the suggested 0.002 where the jet flow then becomes inefficient8.

The radius sizes of the dual radius flap was also based on the GTRI airfoil, but made to fit the supercritical airfoil section smoothly. Fig. 5 shows typical flap setting for the new dual radius airfoil.

\section{B. Three-Dimensional Planform}

The basic wing planform for the circulation control wing was based on the wing planform of the Model 114 ESTOL vehicle concept created by the California Polytechnic State University, San Luis Obispo "SWAT" team in conjunction with NASA Ames ESTOL sector as an ESTOL study reference vehicle during the summer of $2004^{47}$.

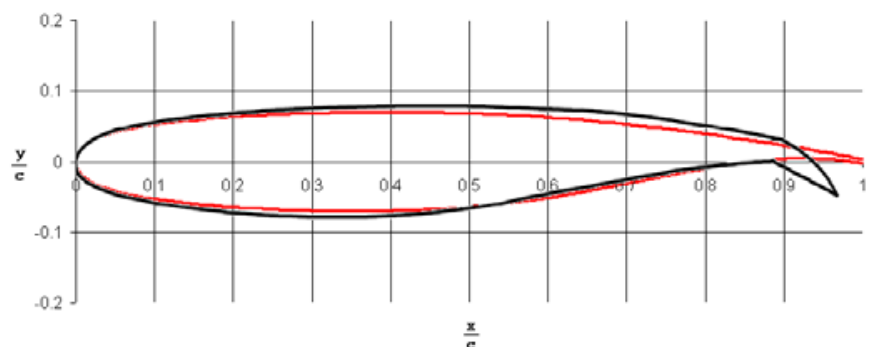

Figure 3. Comparison of GTRI Dual Radius Airfoil with 30 deg flap (black) to NASA SC(2)-0414(red)

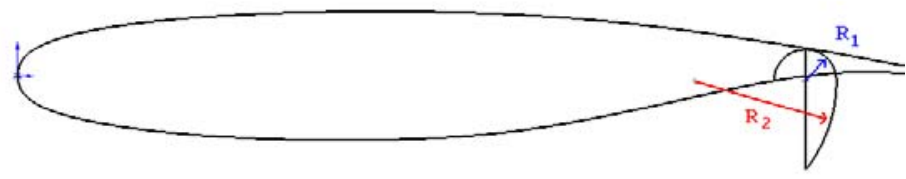

Figure 4. Baseline NASA SC(2)-0414 Supercritical Airfoil with Superimposed Dual Radius Flap,

$R_{1} / c=0.0341, R_{2} / c=0.1544$

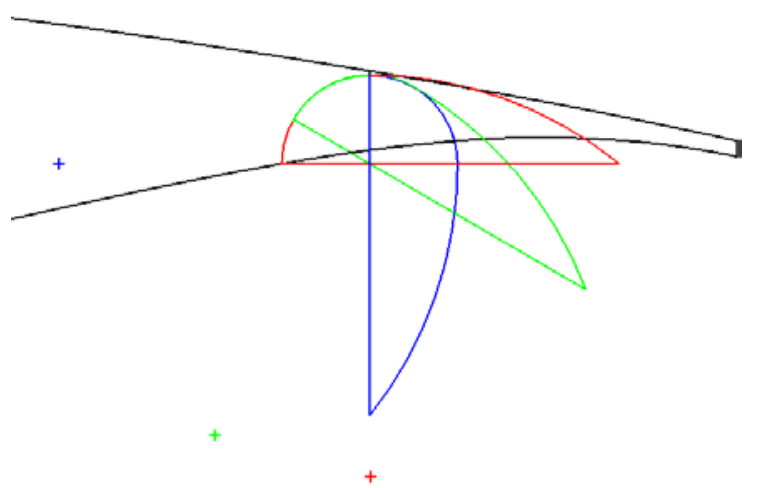

Figure 5. Dual radius Flap Positions,

Red $=0^{\circ}$, Green $=30^{\circ}$, Blue $=90^{\circ}$ and original SC(2)-0414 (Black) 


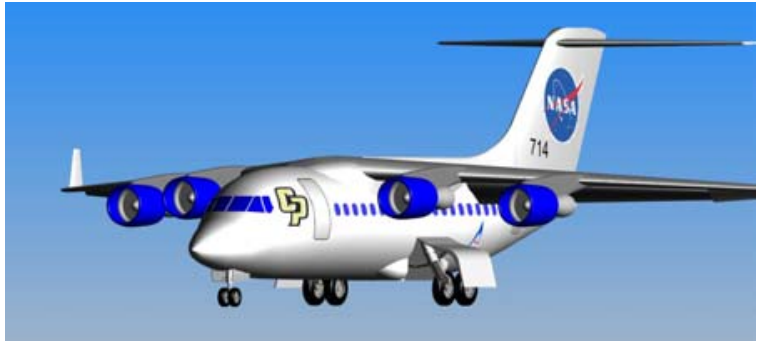

Figure 6. Model 114 ESTOL Concept

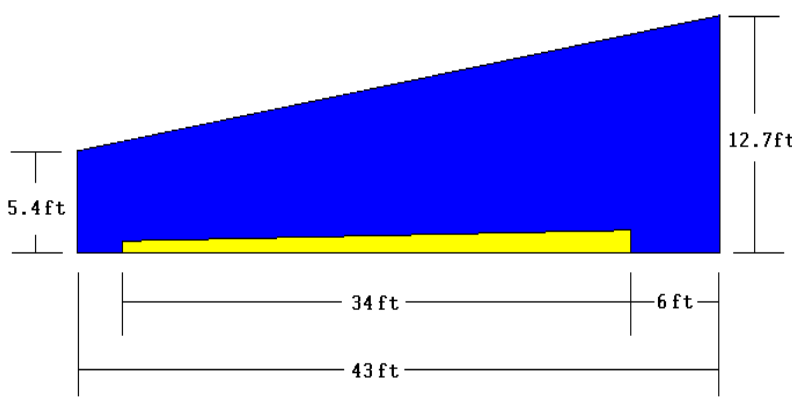

Figure 7. Circulation Control Wing Planform (half-

The Model 114 is a 100 passenger ESTOL aircraft with a wing span of 86 feet. The wing planform of the circulation control model is similar in size starting with a root chord of 12.7 feet, a tip chord of 5.4 feet, and a total span of 86 feet which equates to a taper ratio of 0.425 , a wing reference area of 781 square feet and an approximate aspect ratio of 9.5. The dual radius flap takes up about ten percent of the trailing edge of the wing and accounts for 80 percent of the span. The span-wise inboard location of the flap is 6 feet from the root chord and the outboard location is 40 feet from the root chord this creates a reference flap area of 61.2 square feet for the entire wing. The wing planform can be seen in Fig. 6 .

\section{Computational Fluid Dynamics Model}

\section{A. Solver}

The commercially available computational fluid dynamics code FLUENT 6.2.16 was used for this study. For all flow types, FLUENT will solve conservation equations for mass and momentum. The equation for the conservation of mass is the general form and is valid for both incompressible and compressible flow.

$$
\frac{\partial \rho}{\partial t}+\nabla \cdot(\rho \vec{v})=S_{m}
$$

where $S_{m}$ is added mass in phase modeled flow (which in this case does not apply and will therefore be set to zero). In addition, the conservation of momentum equation is:

$$
\frac{\partial}{\partial t}(\rho \vec{v})+\nabla \cdot(\rho \vec{v} \vec{v})=-\nabla p+\nabla \cdot(\overline{\bar{\tau}})+\rho \vec{g}+\vec{F}
$$

where $p$ is the static pressure, $\vec{F}$ consists of external body forces, $\rho \vec{g}$ is the gravitational body force and $\overline{\bar{\tau}}$ is the stress tensor defined as:

$$
\overline{\bar{\tau}}=\mu\left[\left(\nabla \vec{v}+\nabla \bar{v}^{T}\right)-\frac{2}{3} \nabla \cdot \vec{v} I\right]
$$

where $\mu$ is the molecular viscosity, I is the unit tensor, and $\nabla \vec{v}^{T}$ takes into the account of volume dilation when appropriate. The three-dimensional, steady, segregated, implicit solver setting with cell-based discretization scheme was used simplifying Equations 1-3 accordingly. The segregated solver was chosen because of the low speed flow around the wing and to reduce computer CPU time because of the limited computational resources.

In addition to the basic solver settings, a turbulence model needed to be incorporated because of the unsteady, irregular motion of flow at the jet slot boundary and other sharp corners. The Spalart-Allmaras turbulence model was used with the default values because it is designed specifically for aerospace applications involving wall 
bounded flows and has shown good results for boundary layers that are subjected to adverse pressure gradients. The Spalart-Allmaras turbulence model uses the Boussinesq approach to relate Reynolds stresses to the mean velocity gradient of the flow. In this turbulence model, only one additional transport equation is solved.

$$
\frac{\partial}{\partial t}(\rho \tilde{v})+\frac{\partial}{\partial x_{i}}\left(\rho \tilde{v} u_{i}\right)=G_{v}+\frac{1}{\sigma_{\widetilde{v}}}\left[\frac{d}{d x_{j}}\left\{(\mu+\rho \tilde{v}) \frac{d \tilde{v}}{d x_{j}}\right\}+C_{b_{2}} \rho\left(\frac{\partial \widetilde{v}}{\partial x_{j}}\right)^{2}\right]-Y_{v}+S_{\widetilde{v}}
$$

where $\widetilde{v}$ is identical to the molecular kinematic viscosity except in the near-wall, or viscous-affected, region, $\sigma_{\widetilde{v}}$ and $C_{b_{2}}$ are constants defined by FLUENT, $G_{v}$ is the production of turbulent viscosity, $Y_{v}$ is the destruction of turbulent viscosity that occurs in the near-wall region due to viscous damping. For a more in depth breakdown of how $G_{v}, Y_{v}$ and $\mu$ are calculated, the reader is referred to chapter 11.3 of the FLUENT User's Guide ${ }^{52}$.

This transport equation uses kinematic viscosity as the transport variable to represents turbulent viscosity. It also yields a relatively low computational cost associated with the calculation of the turbulent viscosity. Also beneficial for this application, FLUENT allows the Spalart-Allmaras model to be integrated with wall bounded functions when the resolution is not adequately fine, or is not needed to be fine. When the mesh is fine enough near the wall to resolve a laminar sublayer, the shear stress is obtained from an equation relating stress and strain. When the mesh is too coarse, the law of the wall is employed.

\section{B. Grid Details}

The solid model of the wing was created in Solidworks 2004 and imported into GAMBIT 2.2.30, the companion preprocessor software to FLUENT 6.2.16. Only half of the wing was used for the CFD model in order to cut down on computational time. The solid model can be seen below in Fig. 8 and includes a close up of the dual radius flap and ejection slot.

All of the meshed models were

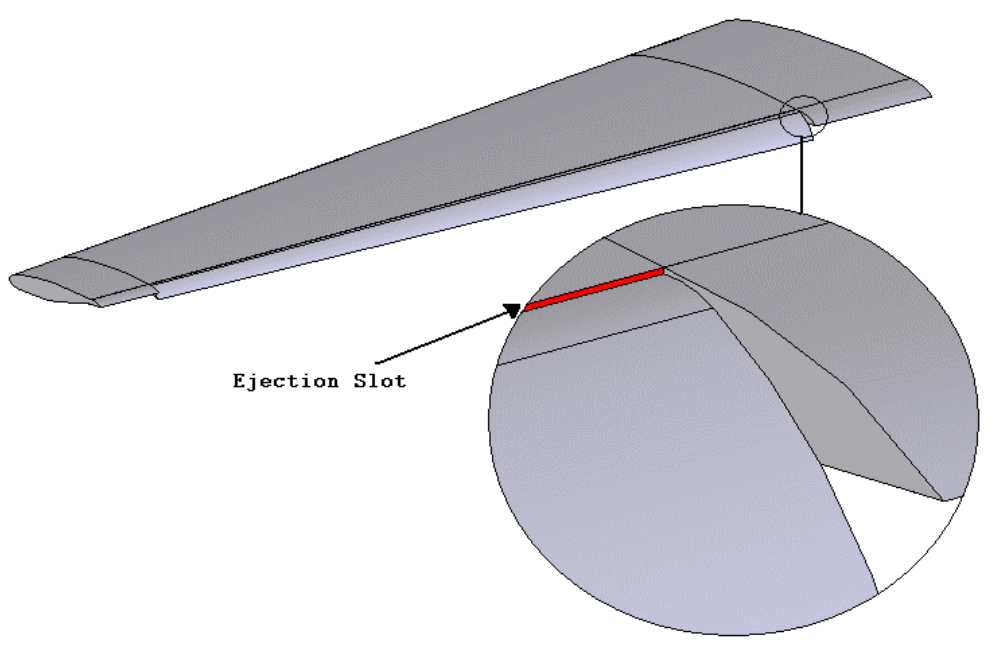

Figure 8. Solid Model of Circulation Control Wing with Ejection Slot Detail ejection slot and the adjoining faces would fail to mesh due to lack of more memory. After all of the faces were meshed a three dimensional flow domain was created around the geometry. This was done by creating a conical shape in the $x-z$ plane using a vertex about 7 chord lengths in front of the leading edge 7 chord lengths in back of the trailing edge and 10 chord lengths outboard of the root chord. The general shape can be seen below. This new face was then rotated around the z-axis to create the three dimensional space. 

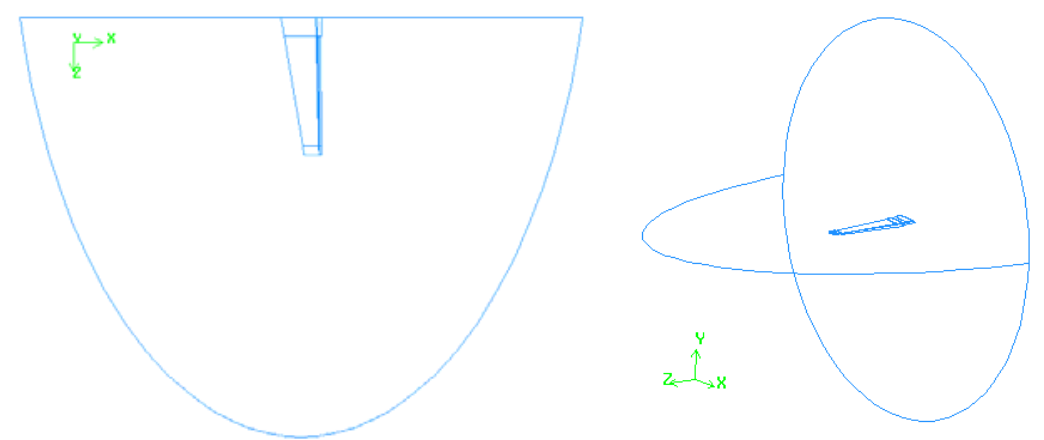

Figure 9. Wing with Computational Domain: a) Planform View (left) and b) 3-D View (right)

Next, the boundary faces were meshed using a Meshing size function from GAMBIT, which specifies the maximum mesh element edge length as a function of distance from a given source entity and uses a non-constant start size, based on the size of the edge meshes on the root chord and a growth rate of 1.2. Finally the volume was meshed using Tet/Hybrid mesh elements which means the mesh will be comprised of mainly tetrahedral elements but may include hexahedral, pyramidal, and wedge elements where appropriate again with a pave scheme. The meshed plane of symmetry can be seen below as well as the final volume mesh.

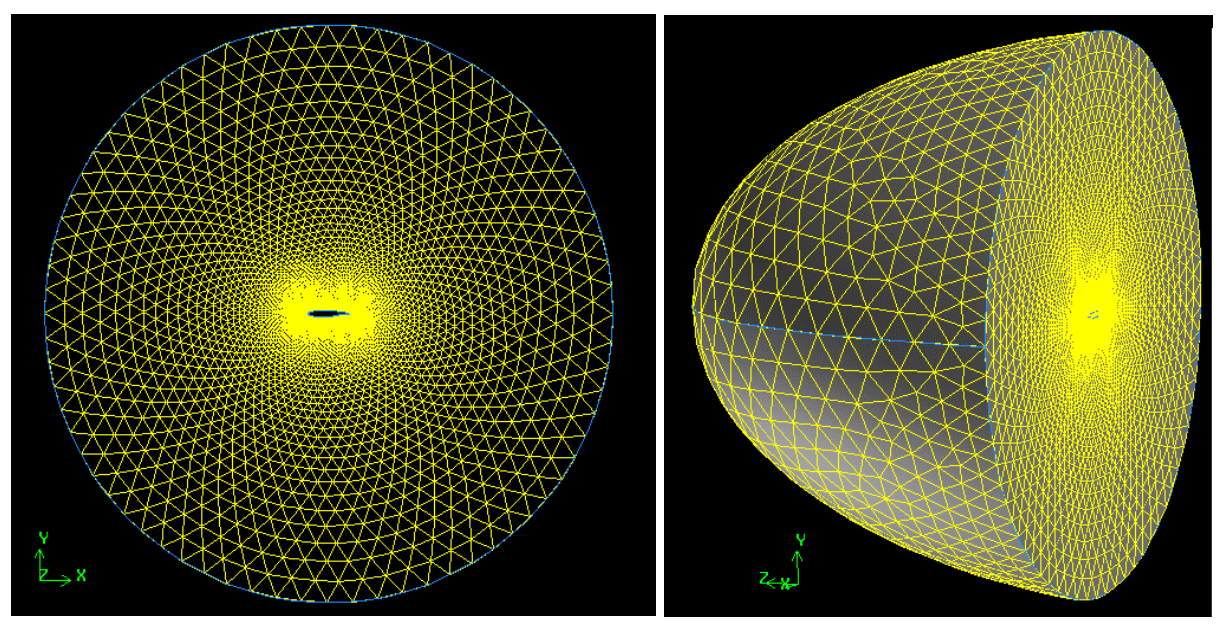

Figure 10. a) Meshed Plane-of-Symmetry (left) and b) Meshed Volume (right)

\section{Grid Sensitivity}

A few test cases were run in order to obtain a high enough fidelity grid for the purpose of the study. The first case was a wing at zero angle-of-attack, zero blowing coefficient from the jet slot, and zero flap deflection angle. The baseline grid size was comprised of 1.6 million elements, and the case was run until the lift and drag forces leveled out. The results of which can be seen below in Table 1. Next the solution was started with the same original grid, but this time a dynamic grid adaption was implemented. The grid was adapted based on the gradient wall shear stress. Every fifty iterations the program would calculate the wall shear stress gradient and refine the top twenty percent of cells with the largest gradient. This solution was also ran until the lift and drag forces leveled out. Lastly, another adaption, this time based on pressure gradient was solved. Again, every fifty iterations the program would calculate the pressure gradient and this time refine the top 50 percent of cells. This higher percent of refined cells is due to the smaller range of pressure gradients than with wall shear stress.

This entire process was repeated for a second case where there was a zero angle-of-attack, but now the flap deflection angle was 90 degrees and the blowing coefficient was 0.0095 , which corresponds to a mass flow rate through the ejection slot of $2 \mathrm{~kg} / \mathrm{s}$. The results of this grid comparison can be seen in the table below. 
Table 1. Grid Adaption Comparison

\begin{tabular}{llllllll}
\hline $\begin{array}{l}\text { Angle-of } \\
- \text { Attack }\end{array}$ & $\begin{array}{l}\text { Flap } \\
\text { Deflection } \\
\text { Angle }\end{array}$ & $\begin{array}{l}\text { Blowing } \\
\text { Coefficient } \\
\mathrm{C}_{\mu}\end{array}$ & $\begin{array}{l}\text { Lift } \\
\text { Coefficient } \\
\mathrm{C}_{\mathrm{L}}\end{array}$ & $\begin{array}{l}\text { Drag } \\
\text { Coefficient } \\
\mathrm{C}_{\mathrm{D}}\end{array}$ & $\begin{array}{l}\text { Lift } \\
\text { Drag Ratio } \\
\text { L/D }\end{array}$ & $\begin{array}{l}\text { Adaption } \\
\text { Cell } \\
\text { Count }\end{array}$ \\
\hline $\mathrm{deg}$ & $\mathbf{d e g}$ & --- & --- & --- & --- & --- & --- \\
\hline $\mathbf{0}$ & $\mathbf{0}$ & $\mathbf{0}$ & $\mathbf{0 . 3 2 4 5}$ & $\mathbf{0 . 0 4 0 2}$ & $\mathbf{8 . 0 6 6}$ & none & 1600292 \\
\hline $\mathbf{0}$ & $\mathbf{0}$ & $\mathbf{0}$ & $\mathbf{0 . 3 2 8 2}$ & $\mathbf{0 . 0 3 7 7}$ & $\mathbf{8 . 7 0 1}$ & pressure & 1663042 \\
\hline $\mathbf{0}$ & $\mathbf{0}$ & $\mathbf{0}$ & $\mathbf{0 . 3 2 5 7}$ & $\mathbf{0 . 0 4 0 2}$ & $\mathbf{8 . 1 1 1}$ & shear stress & $\mathbf{1 8 3 2 5 5 9}$ \\
\hline $\mathbf{0}$ & $\mathbf{9 0}$ & $\mathbf{0 . 0 0 9 5}$ & $\mathbf{0 . 9 6 9 5}$ & $\mathbf{0 . 1 4 9 1}$ & $\mathbf{6 . 5 0 3}$ & none & $\mathbf{1 2 1 7 1 7 4}$ \\
\hline $\mathbf{0}$ & $\mathbf{9 0}$ & $\mathbf{0 . 0 0 9 5}$ & $\mathbf{0 . 9 6 7 1}$ & $\mathbf{0 . 1 4 3 1}$ & $\mathbf{6 . 7 5 7}$ & pressure & $\mathbf{1 3 0 6 0 3 8}$ \\
\hline
\end{tabular}

Based on the above results the decision was made to omit grid adaption for this study in order to save computational time because the information that was relevant to the study did not change significantly. The largest difference being 6.2 percent decrease in drag coefficient from no adaption to pressure adaption in the zero angle-ofattack, zero blowing coefficient and zero flap deflection case.

In addition to dynamic grid adaption an examination into the grid's $y+$ sensitivity was investigated. This examination suggested that the values of $y+$ before the jet slot on the upper surface of the wing may be too broad for the chosen turbulence model to exactly resolve the boundary layer in this region, but more in depth studies will need to be investigated in the future to determine the influence this has on the solutions.

\section{Boundary Conditions}

The flow field was set to be a pressure-far-field boundary, meaning pressure, Mach number, temperature, and flow direction were specified. The pressure and temperature were set to $101325 \mathrm{~Pa}$ and $288.16^{\circ} \mathrm{K}$ respectively, standard day values at sea level. Since the basis of this study is to test the effects of Circulation Control on lift during take-off and landing in order to shorten runway distances the Mach number was set to 0.178 . This was done because a typical ESTOL aircraft has a cruise Mach number of 0.8 and a cruise altitude of 30,000 feet. Also, takeoff velocity and approach velocity are between 1.2-1.3 times the stall velocity (Equations 5-7), where the stall velocity can be approximated at about 0.2 times the cruise velocity (Equation 8).

$$
\begin{gathered}
V_{T O}=1.2 V_{\text {Stall }} \\
V_{\text {app }}=1.3 V_{\text {Stall }} \\
\therefore V_{\text {Study }}=1.25 V_{\text {Stall }} \\
V_{\text {Stall }} \approx 0.2 V_{\text {cruise }} \\
V_{\text {cruise }}=a_{\text {cruise }} * M_{\text {cruise }}
\end{gathered}
$$

Combing the above:

$$
M_{\text {study }}=\frac{V_{\text {study }}}{a_{\text {study }}}=\frac{1.25 V_{\text {stall }}}{a_{\text {study }}}=\frac{(1.25)\left(0.2 V_{\text {cruise }}\right)}{a_{\text {study }}}=\frac{(1.25)(0.2)\left(a_{\text {cruise }} * M_{\text {cruise }}\right)}{a_{\text {study }}}=0.25 \frac{a_{\text {cruise }}}{a_{\text {study }}} M_{\text {cruise }}
$$


where

$$
\frac{a_{\text {cruise }}}{a_{\text {study }}}=\frac{\sqrt{\gamma R T_{\text {cruise }}}}{\sqrt{\gamma R T_{\text {study }}}}=\sqrt{\frac{T_{\text {cruise }}}{T_{\text {study }}}}
$$

Therefore

$$
M_{\text {study }}=0.25 \sqrt{\frac{T_{\text {cruise }}}{T_{\text {study }}}} M_{\text {cruise }}
$$

The jet slot was then set as a mass flow inlet. This means that the mass flow rate was specified and the blowing coefficient was calculated from that. In order to calculate the blowing coefficient the following equations were used:

$$
C_{\mu}=\frac{V_{j e t} * \dot{m}}{S_{r e f} * \frac{1}{2} \rho_{\infty} V_{\infty}^{2}}
$$

where

$$
\dot{m}=\rho_{j e t} V_{j e t} A_{j e t}
$$

is the mass flow rate of the jet. The jet density is the average value of the density on the entire ejection slot face. Lastly air is chosen from the list of material options in FLUENT and the density is changed from a constant value to be calculated based on ideal gas properties.

\section{Results and Discussion}

\section{A. Solver Validation}

In order to validate the solver settings, a comparison was made to the lift generated in one of the GTRI studies. This study ${ }^{18}$ gave the results of different blowing coefficients on a dual-radius Circulation Control airfoil at zero degrees angleof-attack with a thirty degree flap deflection angle. The freestream flow conditions were set as follows: pressure of $97906 \mathrm{~Pa}$, density of 1.1596 $\mathrm{kg} / \mathrm{m}^{3}$, velocity of $28.74 \mathrm{~m} / \mathrm{sec}$ and a corresponding Mach number of 0.0836 . These conditions were matched in FLUENT and the rest of the solver was set as mentioned before. The outcome was then compared to the data from GTRI and the resulting comparison can be seen below in Fig 11.

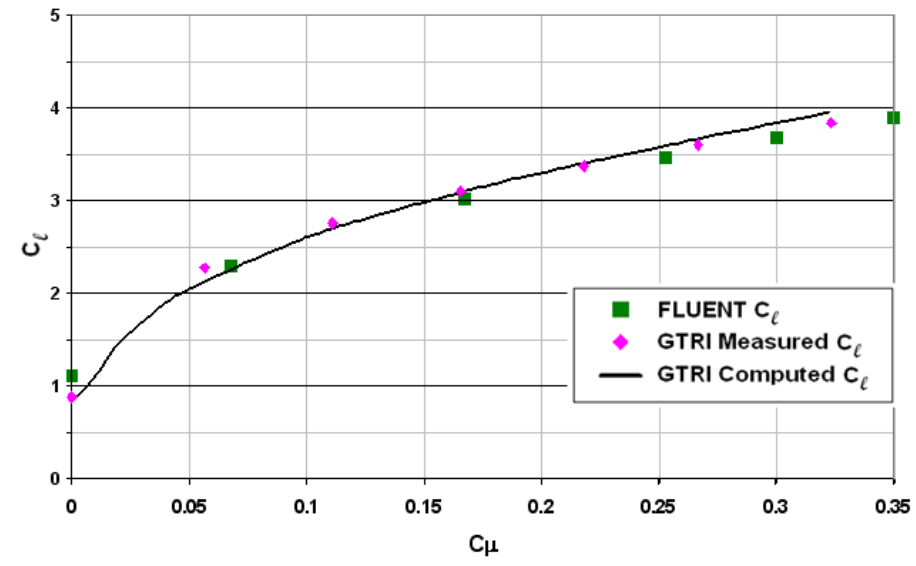

Figure 11. Two-Dimensional Lift Comparison with GTRI Data

The acquired CFD results match extremely well with the GTRI data even considering the airfoils are slightly different in shape and the jet slot locations and jet slot height ratios vary: $\mathrm{x} / \mathrm{c}=88.75 \%$ and $\mathrm{h} / \mathrm{c}=0.0019$ for GTRI and $\mathrm{x} / \mathrm{c}=89.86 \%$ and $\mathrm{h} / \mathrm{c}=0.0016$ for this case. These results validate the use of the solver settings for the rest of this study. 


\section{B. Two-Dimensional Analysis}

In order to fully understand the results to follow, an understanding of the flow physics in a cross section of a Circulation Control wing is needed. First, a look at the Mach number contours reveal that the flow is indeed in the incompressible regime, with a Mach number $\leq 0.2$, except right where the flow exits the jet slot. This flow then mixes so quickly with the low speed flow on the boundary that any compressibility effects are negligible for this study. Fig. 12 is a pressure contour plot for a two-dimensional airfoil with thirty degree flap deflection and zero blowing at an angle-of-attack of six degrees.

The results are typical for a normal airfoil at a positive angle-of-attack, with low pressure on the top and high pressure on the bottom. In addition, the path lines, colored by pressure coefficient, for the airfoil are shown below in Fig. 14. Next, by introducing air into the flow from the ejection slot at a blowing coefficient of 0.05 , the pressure contours are altered, and that change can be seen below. It can be seen by comparing Fig. 12 and Fig 13 that the pressure increases on the bottom of the airfoil when blowing is introduced. Also, a low pressure region begins to develop near the jet slot. By increasing the blowing even more, the pressure changes as shown in Fig. 15. Once again it can be seen that the pressure is increasing below the airfoil, even near the leading edge of the airfoil, due to the flow from the ejection slot. Also, for comparison, the path lines for the blowing coefficient of 0.08 are shown below in Fig 16..Finally, as a graphical comparison between the three cases of blowing coefficients, visualized above with Fig. 12, Fig. 13 and Fig. 15, a plot was created of the pressure coefficient values against the chord location on the airfoil.

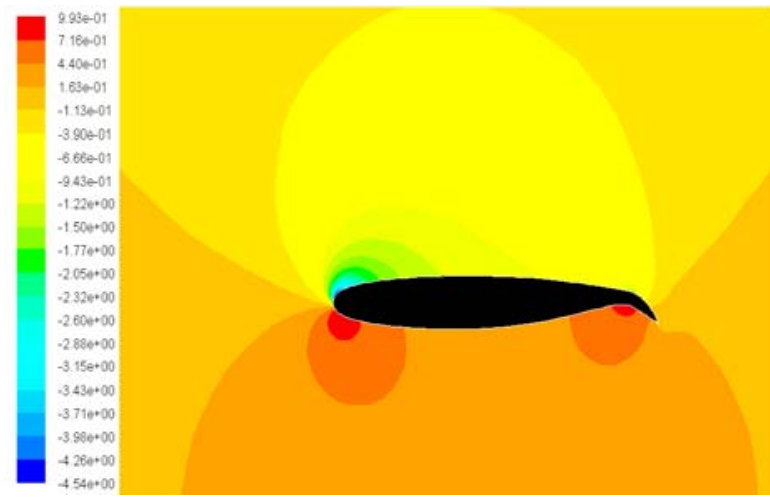

Figure 12. Pressure Coefficient Contours for $C_{\mu}=$ 0.00, Angle-of-Attack $=6^{\circ}$ and Flap Deflection $=30^{\circ}$
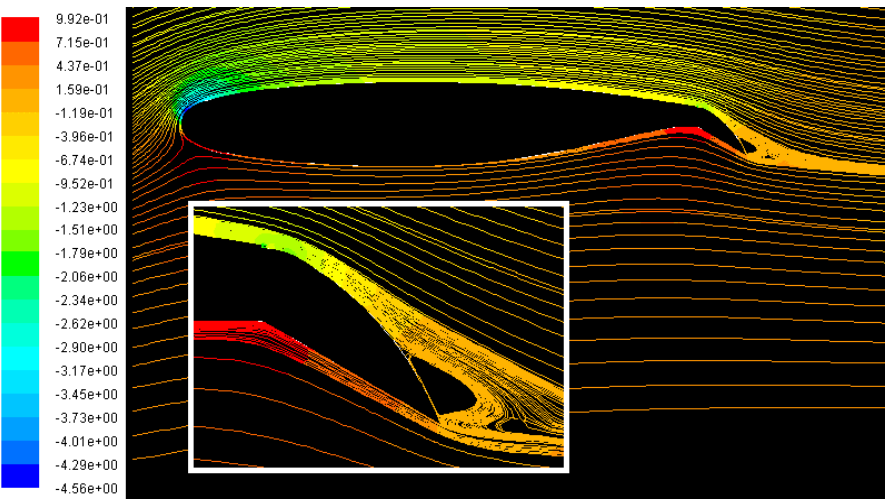

Figure 14. Path Lines Colored by $C_{P}$ for $C_{\mu}=0.00$, Angleof-Attack $=6^{\circ}$ and Flap Deflection $=30^{\circ}$

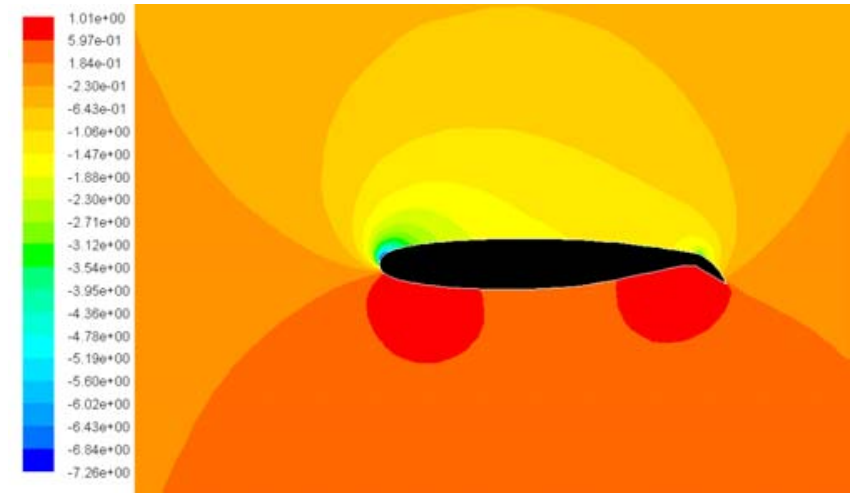

Figure 13. Pressure Coefficient Contours for $C_{\mu}=0.05$, Angle-of-Attack $=6^{\circ}$ and Flap Deflection $=30^{\circ}$

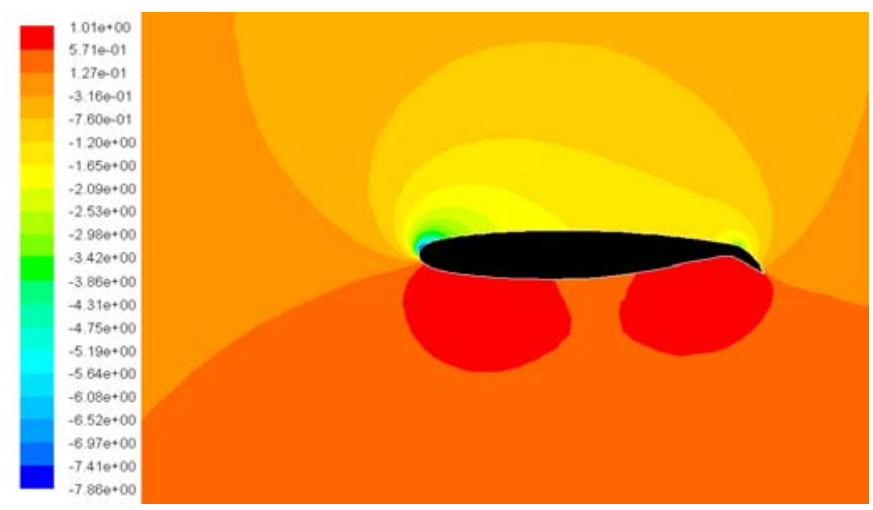

Figure 15. Pressure Coefficient Contours for $C_{\mu}=0.08$, Angle-of-Attack $=6^{\circ}$ and Flap Deflection $=30^{\circ}$ 

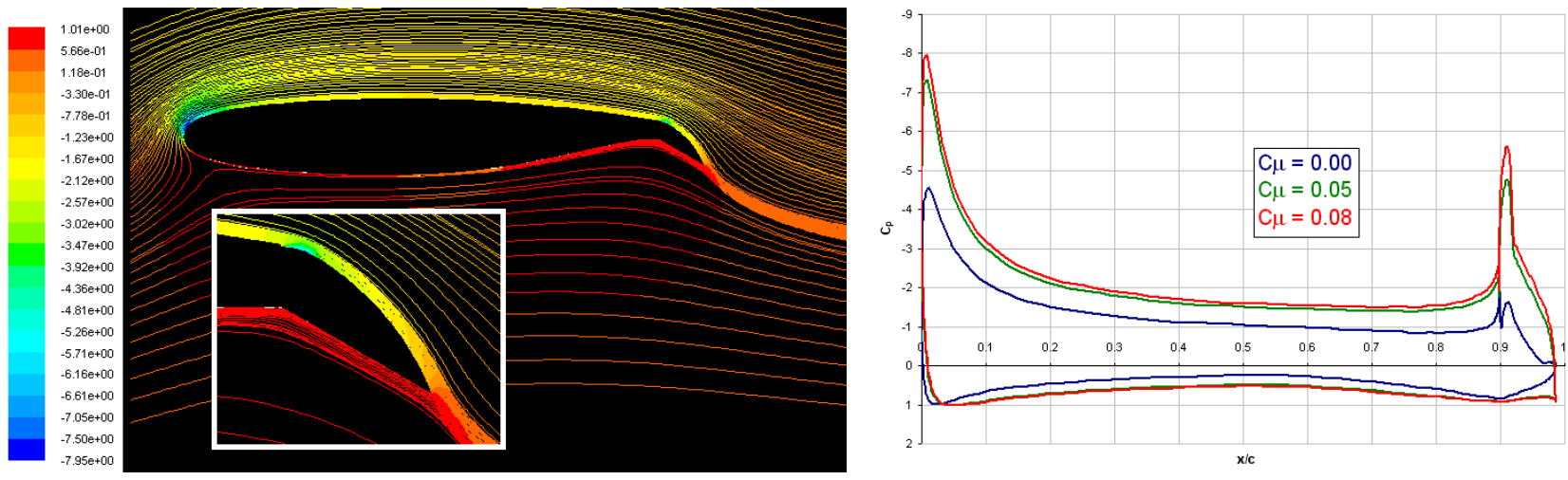

Figure 16. Path Lines Colored by $C_{P}$ for $C_{\mu}=0.08$, Angleof-Attack $=6^{\circ}$ and Flap Deflection $=30^{\circ}$

Figure 17. Pressure Coefficients for Angle-ofAttack $=6^{\circ}$ and Flap Deflection $=30^{\circ}$

\section{Three-Dimensional Lift and Drag}

Lift and drag data were compiled for a range of three-dimensional cases. Again, each one of the cases was run with the previously mentioned boundary conditions, including sea level pressure and temperature for standard day and a Mach number of 0.178. Also beneficial to remember is that the flow is indeed incompressible because the flow exiting the jet slot mixes so quickly that any compressible effects from the high speed jet flow are negligible. These cases varied angle-of-attack, flap deflection angle and blowing coefficient. By varying the blowing coefficient for any given angle-of-attack and flap deflection angle, the lift coefficient will increase until a stall angle is reached. The results for the zero flap deflection case can be seen below in Fig. 18.

The graph shows the variation in lift due to angle-of-attack for a range of blowing coefficients. It can be seen that lift coefficients up to 2.3 can be achieved for the Circulation Control wing that has zero flap deflection just by the introduction of high speed air by way of the ejection slot. The lift curve slopes for each of the blowing coefficients are very similar to each other, increasing from $4.43 / \mathrm{rad}(0.71 \pi / \mathrm{rad})$ for the $\mathrm{C}_{\mu}=0.0$ blowing case to $5.11 / \mathrm{rad}(0.81 \pi / \mathrm{rad})$ for the $\mathrm{C}_{\mu}=0.35$ blowing case. It is interesting to note the jump in lift between a blowing coefficient of 0.02 and 0.15 . This jump is due to the doubling in mass flow rate from the prior to the latter blowing coefficient. The remainder of the lines representing blowing coefficient do not equate to a doubling in mass flow rate, but rather increase less each time. Fig. 19 shows the drag polar, or lift versus drag, for this case.

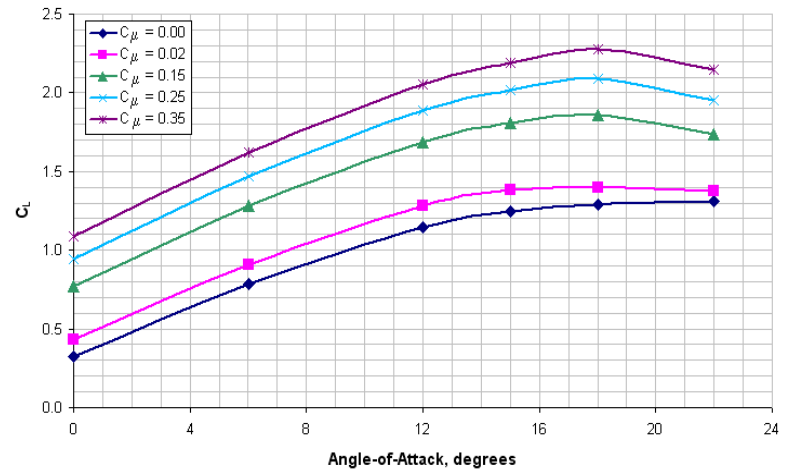

Figure 18. Lift Due to Angle-of-Attack for Dual Radius Flap Deflection Angle $=0^{\circ}$

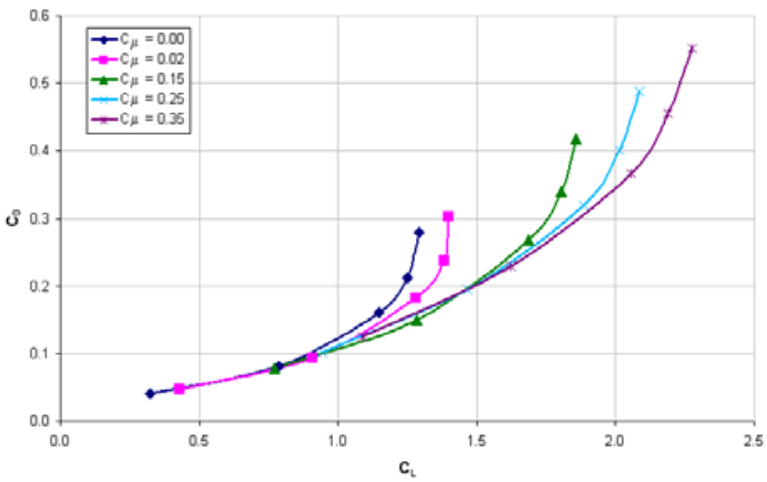

Figure 19. Drag Polar for Dual Radius Flap Deflection Angle of $0^{\circ}$ 
The drag values that are shown here account for the contribution from shear stress and pressure, without subtracting the small portion of thrust associated with the jet slot blowing. It was felt that the thrust portion due to the blowing from the jet slot would be more appropriately addressed from a propulsions standpoint. The drag polar plot follows the typical trend of most wings, where as lift increases, drag increases. Although it should be noted that for some lift values, for example $\mathrm{C}_{\mathrm{L}}=2.0$, the drag can be decreased with a blowing coefficient of 0.35 over a blowing coefficient of 0.25 .

When the dual radius flap is rotated to 30 degrees off the horizontal, the lift significantly increases compared to the previous case. The results of which can be seen below in Fig. 20. The new configuration, with a 30 degree flap deflection angle, generally stalls at lower angles-of-attack when compared to the data of the zero degree deflection angle configuration.

The lift coefficient has increased roughly $40 \%$ over the zero degree flap deflection case to reach values of approximately 3.3. In this case, the lift curve slopes have all decreased when compared to the lift curve slopes from the previous case. Now the slope values are decreasing as blowing increases, not increasing as before: from 3.67/rad $(0.58 \pi / \mathrm{rad})$ for the $\mathrm{C}_{\mu}=0.0$ blowing case to $3.53 / \mathrm{rad}(0.56 \pi / \mathrm{rad})$ for the $\mathrm{C}_{\mu}=0.35$ blowing case. Also, similar to the previous case, the jump in the amount of lift between the blowing coefficients of 0.02 and 0.05 is due to the doubling in mass flow rate from the jet slot. Using these data in conjunction with the drag polar, seen below in Fig. 21, an optimum angle-of-attack and blowing coefficient combination can be determined for this flap deflection angle in order to minimize drag and maximize lift.
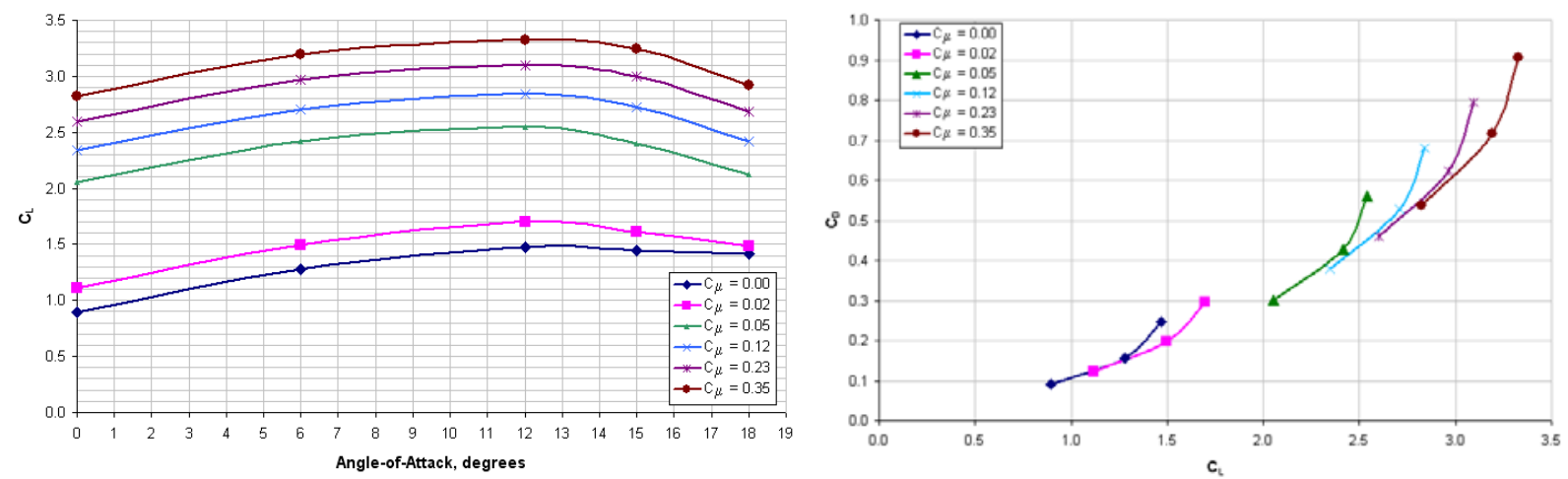

Figure 20. Lift Due to Angle-of-attack for Dual Figure 21. Drag Polar for Dual Radius Flap Radius Flap Deflection Angle $=\mathbf{3 0}^{\circ}$ Deflection Angle of $30^{\circ}$

The drag polar for this case follows the same trend as the previous case, but now the lines, representing different blowing coefficients, overlap less than the previous case of zero flap deflection.

Next, the dual radius was rotated 60 degrees off the horizontal and the same process was repeated. In this situation the maximum lift again increases over the previous two cases but not nearly as significantly as the thirty degree case does over the zero degree case. The results can be seen below in Fig. 22.

In this case, the maximum lift coefficient increased $52 \%$ over the dual radius flap deflection case of zero degrees but only $6 \%$ over the dual radius flap deflection case of thirty degrees. Again, the lift curve slopes for these blowing coefficients are decreasing in value, ranging from $3.73 / \mathrm{rad}(0.59 \pi / \mathrm{rad})$ for the $\mathrm{C}_{\mu}=0.0$ blowing case to $2.05 / \mathrm{rad}$ $(0.33 \pi / \mathrm{rad})$ for the $\mathrm{C}_{\mu}=0.34$ blowing case, and the jump in lift is attributed to mass flow rate. For this flap deflection angle, the drag polar shows that the different blowing coefficients are all producing drag that closely follow a single curved line as shown in Fig. 23. 


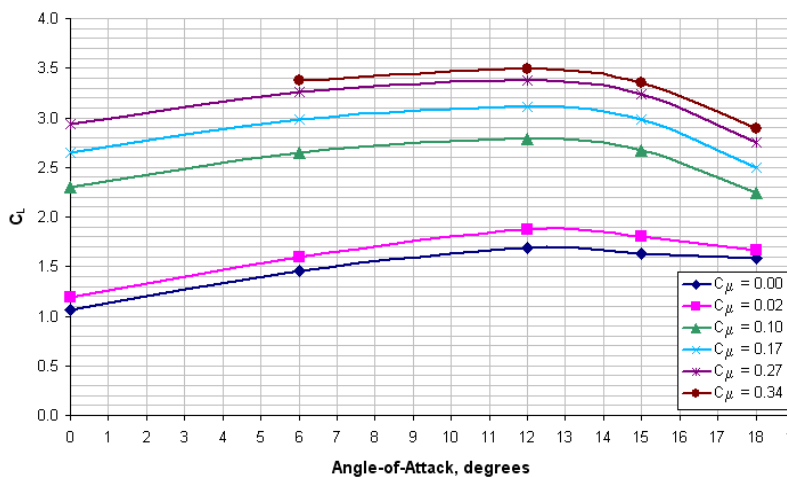

Figure 22. Lift Due to Angle-of-attack for Dual Radius Flap Deflection Angle $=\mathbf{6 0}^{\circ}$

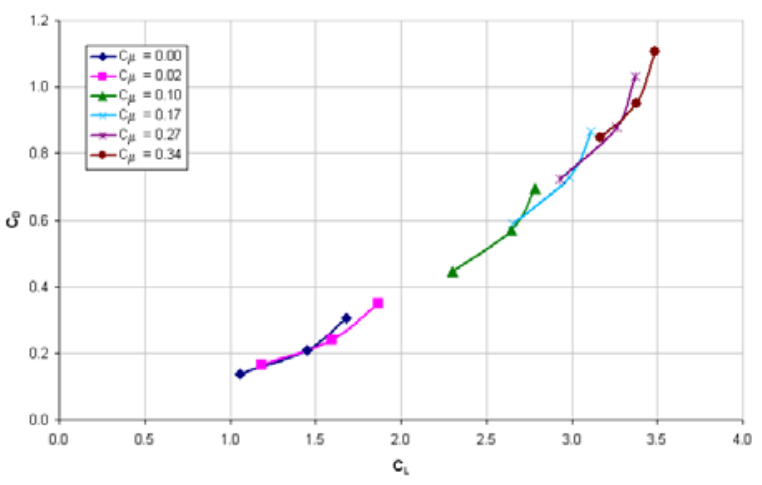

Figure 23. Drag Polar for Dual Radius Flap Deflection Angle of $60^{\circ}$

Lastly, the dual radius flap was rotated to 90 degrees from the horizontal, the results of which can be seen below in Fig. 24. In this case, the lift does not continue to increase, as was the trend in the last three cases. This demonstrates that there is a flap deflection angle somewhere between sixty degrees and ninety degrees where there is no more effective increase in lift and it is therefore unnecessary to ever deflect to such an angle when lift is a driving factor.

In this last case, the maximum lift coefficient is only about $7 \%$ higher at 2.45 than the original maximum lift coefficient for the dual radius flap deflection angle of zero degrees. The lift curve slopes have increased in value when compared to the previous case, but still continue to decrease within the increasing blowing coefficient range. The lift curve slopes range from $3.12 / \mathrm{rad}(0.50 \pi / \mathrm{rad})$ for the $C_{\mu}=0.0$ blowing case to $2.87 / \mathrm{rad}(0.46 \pi / \mathrm{rad})$ for the $\mathrm{C}_{\mu}=0.34$ blowing case and once again the large gap between the blowing coefficients of 0.02 and 0.10 is due to a doubling in mass flow rate. Also, in conjunction with the lift data, the drag polar for the flap deflection angle of ninety degrees is shown below in Fig. 25.

Again these drag data tends to overlap to form one basic trend line like the previous data for the sixty degree flap deflection. Based on all of the previous data, Circulation Control lift coefficients can be observed to be significantly higher than typical lift coefficients; for example, a typical mechanical flap configuration with a thirty degree flap deflection angle at take-off can reach a maximum lift coefficient of about 1.8 , and this study revealed lift coefficients reaching 3.3, an increase of $83 \%$ over the traditional high-lift systems.

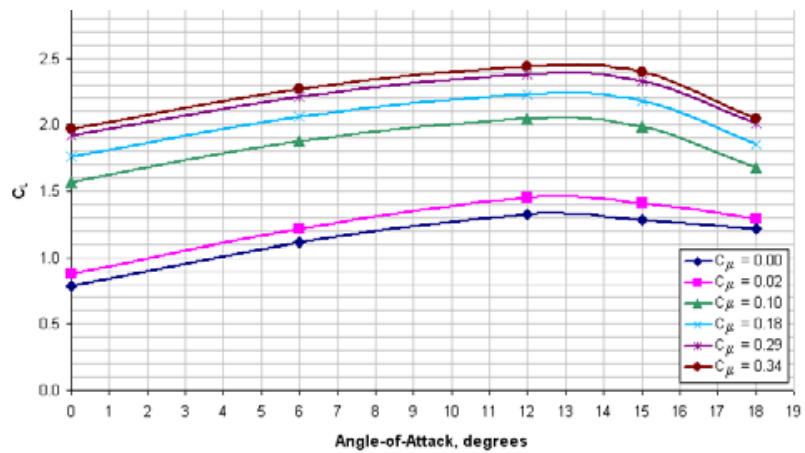

Figure 24. Lift Due to Angle-of-attack for Dual Radius Flap Deflection Angle $=\mathbf{9 0}^{\circ}$

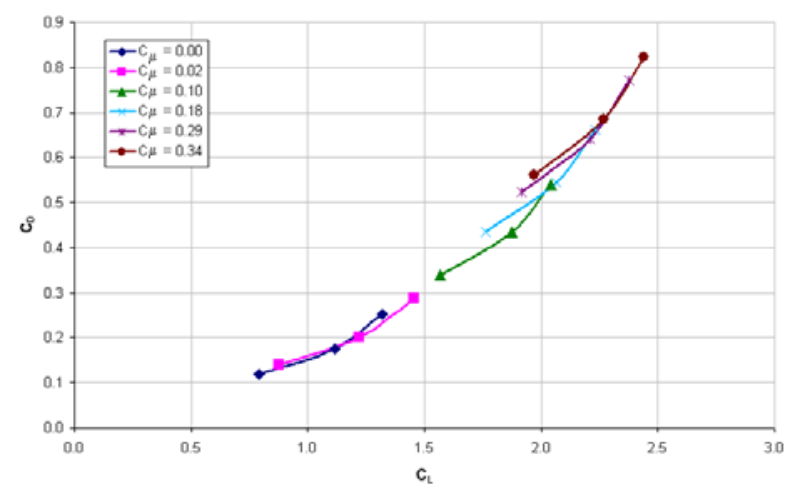

Figure 25. Drag Polar for Dual Radius Flap Deflection Angle of $90^{\circ}$

\section{Balanced Field Length Calculations}

Based on the lift and drag data collected from FLUENT, the balanced field length (BFL) and landing distance could be calculated. The BFL is defined as the total take-off distance, including the obstacle clearance, when one engine fails at the "decision speed", which is defined as the speed where the aircraft can either brake to a halt or 
continue the take-off in the same total distance. For that reason, BFL is a more defining requirement than take-off distance alone. The equation for BFL can be calculated as follows based on equations found in Raymer ${ }^{49}$.

$$
B F L=\left(\frac{0.863}{1+2.3 G}\right)\left(\frac{W / S}{\rho g C_{L_{c l i m b}}}+h_{\text {obstacle }}\right)\left(\frac{1}{T_{A V} / W-U}+2.7\right)+\left(\frac{655}{\sqrt{\rho / \rho_{S L}}}\right)
$$

where

$$
\begin{gathered}
G=\gamma_{c \lim b}-\gamma_{\min } \\
\gamma_{c \lim b}=\sin ^{-1}[(T-D) / W]
\end{gathered}
$$

and the thrust, $\mathrm{T}$, is defined for the one engine out situation.

$$
T_{A V}=0.75 T_{\text {static }}\left(\frac{5+B P R}{4+B P R}\right)
$$

and

$$
U=0.01 C_{L_{\max }}+0.02
$$

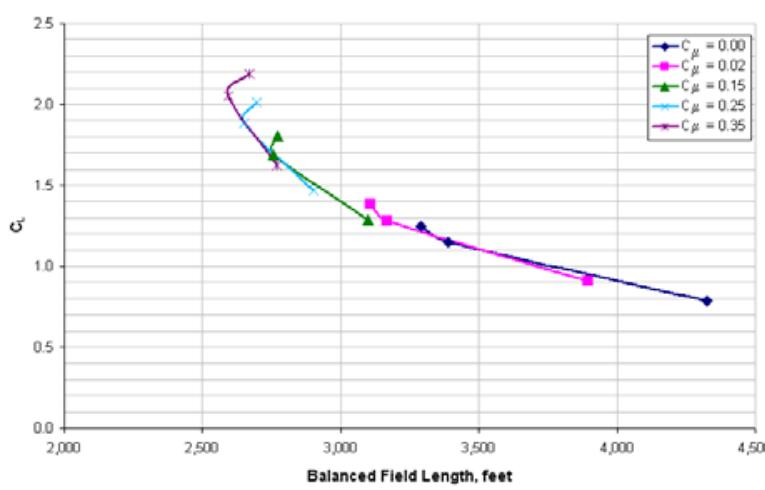

Figure 26. Balanced Field Length for Dual Radius Flap Deflection Angle $=\mathbf{0}^{\circ}$

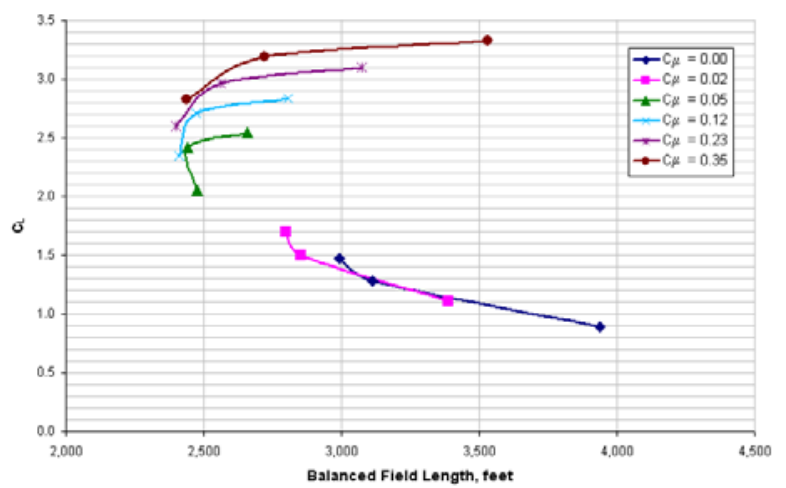

Figure 27. Balanced Field Length for Dual Radius Flap Deflection Angle $=\mathbf{3 0}{ }^{\circ}$

At this point, a few assumptions were made about the aircraft that the Circulation Control wing would occupy. Looking back to representative ESTOL aircraft and especially the Model 114, the wing loading (W/S) was given a value of $80 \mathrm{psf}$, an average value for this type of aircraft. Similarly, a thrust to weight ratio (T/W) of 0.5 was chosen. These compare to the values of the Model 114 of 72.4 psf and 0.485 for the wing loading and thrust to weight ratio respectively. Next the obstacle height, $h_{\text {obstacle }}$ was set at 35 feet, which is the standard FAA requirement for commercial aircraft. $\mathrm{C}_{\mathrm{Lmax}}$ was determined from the above lift versus angle-of-attack graphs for every line of varying blowing coefficient. Finally, the thrust for the engine was chosen to be produced by four bypass ratio (BPR) 5 engines, just as the Model 114 has. The choice of four engines then set the minimum climb 
angle, $\gamma_{\min }$, to 1.719 degrees, based on the one engine out requirement ${ }^{49}$. The graph in Fig. 26 helps to visualize the effect of lift on BFL. This particular graph is for a flap deflection angle of zero degrees.

As the blowing coefficient is increased, the lift increases and, therefore, the BFL decreases. This trend continues until the drag becomes too large and then, the BFL begins to increase again. The smallest BFL is about 2,600 feet, and that corresponds to a climb out angle of 9.2 degrees and a blowing coefficient of 0.35 . Next the same plot was produced for the flap deflection angle of thirty degrees.

By rotating the deflection angle of the dual radius flap to thirty degrees, the increase in lift, shown in Fig. 20, causes a desirable decrease in BFL as seen above in Fig. 27. In this plot, the effects from drag can be seen to have a much larger influence on BFL at higher lift coefficients. Now the smallest BFL is 2,400 feet, a decrease from the dual radius deflection angle of zero degrees by 200 feet. Again BLF calculations were made for a dual radius deflection angle of sixty degrees and those results can be seen below in Fig. 28.

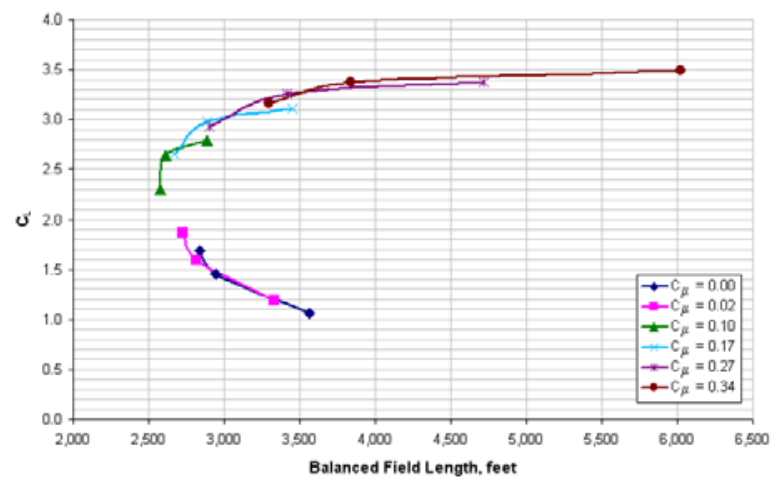

Figure 28. Balanced Field Length for Dual Radius Flap Deflection Angle $=\mathbf{6 0}^{\circ}$

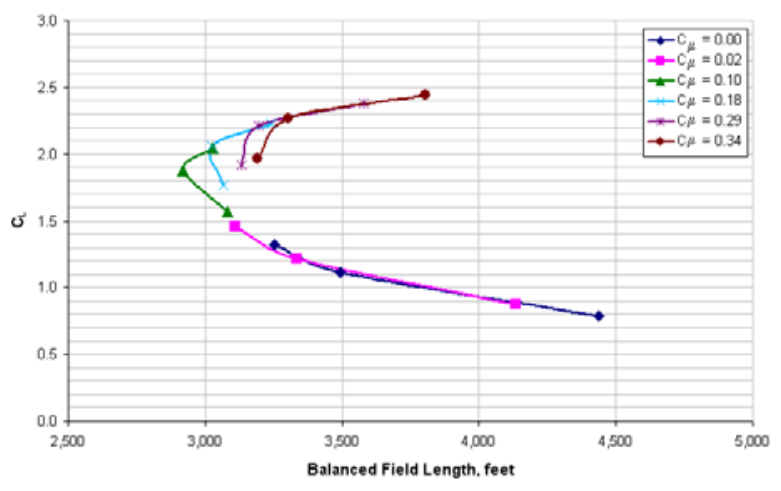

Figure 29. Balanced Field Length for Dual Radius Flap Deflection Angle $=\mathbf{9 0}^{\circ}$

In this case, the shortest BFL has increased over the last case, because of the increasing drag forces. There is obviously a minimum BFL for this flap setting and that lies somewhere in the 2,600 feet range, which is the same distance as the shortest BFL for the flap deflection angle of zero degrees, again a 200 feet increase over the BFL for the last case. Lastly, BFLs were calculated for the dual radius flap deflection angle of ninety degrees shown in Fig. 29.

The shortest BFL for the ninety degree flap deflection case is almost 3,000 feet, which has increased over the last case because of the decreased lift and increased drag explained in the previous paragraphs. The ninety degree case also follows the same trend as the sixty degree case, which was expected especially since the ninety degree case has less lift. Based on the above equations and graphs, the best BFL was calculated to be 2,400 feet. This length easily meets the NASA ESTOL mission requirement of 2,000-3,000 $\mathrm{feet}^{46}$. This BFL is for the flap deflection angle of 30 degrees, climb-out angle of just over six degrees and blowing coefficient of 0.23 . While this is the shortest calculated distance, it should also be noted that a wide range of blowing coefficients and flap settings are capable of achieving the NASA specified mission requirements.

\section{E. Landing Distance Calculations}

In addition to the BFL, the landing distance was determined. The equations for landing distance were found in Brandt ${ }^{50}$ and are as follows:

$$
S_{\text {Land }}=\frac{1.69 W_{L}^{2}}{\rho S_{r e f} C_{L_{\max }} g\left[D+\mu_{\text {brake }}\left(W_{L}-L\right)\right]}
$$

where 


$$
D=\frac{1}{2} \rho_{\infty} V_{\infty}^{2} S_{r e f} C_{D}
$$

and

$$
L=\frac{1}{2} \rho_{\infty} V_{\infty}^{2} S_{r e f} C_{L}
$$

In this case, the landing weight $\left(\mathrm{W}_{\mathrm{L}}\right)$ was estimated as the take-off gross weight (TOGW) minus the fuel weight, where the fuel weight can be estimated at $20 \%$ of the TOGW. Also, the braking coefficient, $\mu_{\text {brake }}$, for dry concrete is estimated at $0.4^{50}$. Similar to the BFL analysis, landing distance was plotted against lift to visualize the trends. The results of which can be seen below in Fig. 30 for the dual radius flap deflection angle of zero degrees.

This plot shows that the landing distance is far too high for an ESTOL aircraft when the dual radius flap is not deflected, effectively creating a sharp trailing edge. This is one reason why airplanes do not land without some sort of flap deflection or reverse thrusting. A more interesting plot is for the flap deflection angle of thirty degrees which can be seen below in Fig. 31.

For the thirty degree flap deflection case, the lift to drag ratios are too high, meaning there is not enough drag to shorten the landing distance. The shortest runway distance is about 2,800 feet. This means that the flap needs to be deflected more in order to achieve a landing distance below or within the low range of the NASA mission requirement of 2,000 to 3,000 feet. The next plot of interest is the landing distances for the dual radius flap deflected to sixty degrees. This can be seen in Fig. 32.

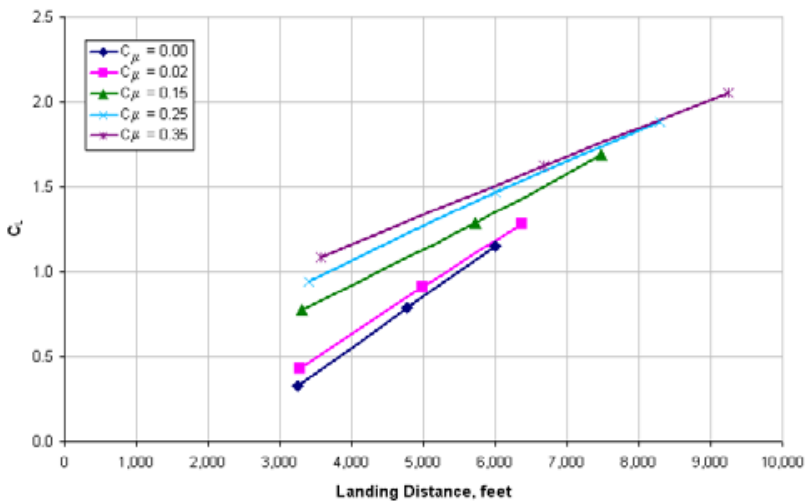

Figure 30. Landing Distance for Dual Radius Flap Deflection Angle $=0^{\circ}$

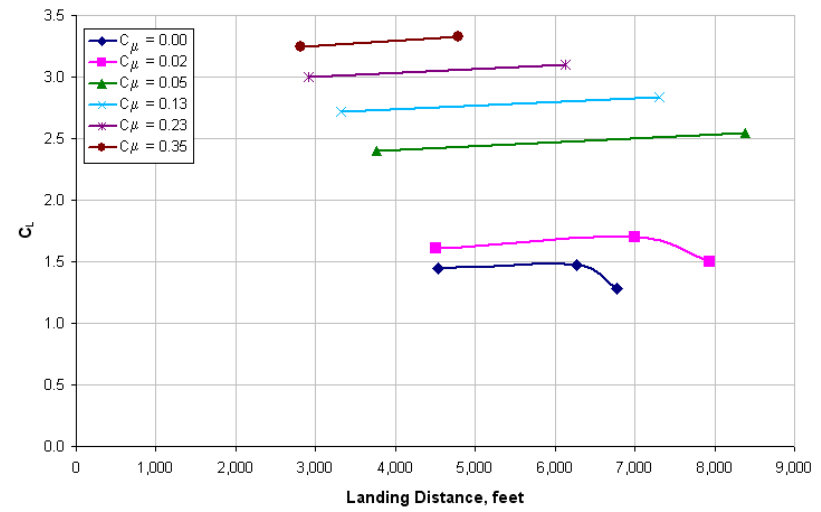

Figure 31. Landing Distance for Dual Radius Flap Deflection Angle $=30^{\circ}$

By deflecting the flap further to sixty degrees, the landing distance does decrease substantially from the previous plot. As lift increases, the landing distance also increases until the drag becomes more effective, then the landing distance decreases until it reaches a minimum value of about 2,150 feet, corresponding to the highest blowing coefficient. Finally, the last thing to look at would be the landing distances for the dual radius flap deflection angle of ninety degrees to see if the distance will continue to decrease.

It can be seen in Fig. 33 that the smallest landing distance is just about 2,000 feet, which is only about 150 feet less than the previous flap setting. On the other hand, there are several more blowing coefficient and lift values, which correspond to angle-of-attack, combinations within the desired 2,000-3,000 foot range, giving the operator a larger window to work with when landing this type of aircraft. Based on the results, the shortest landing distance this type of aircraft is capable of is 2,000 feet for a flap deflection angle of ninety degrees. 

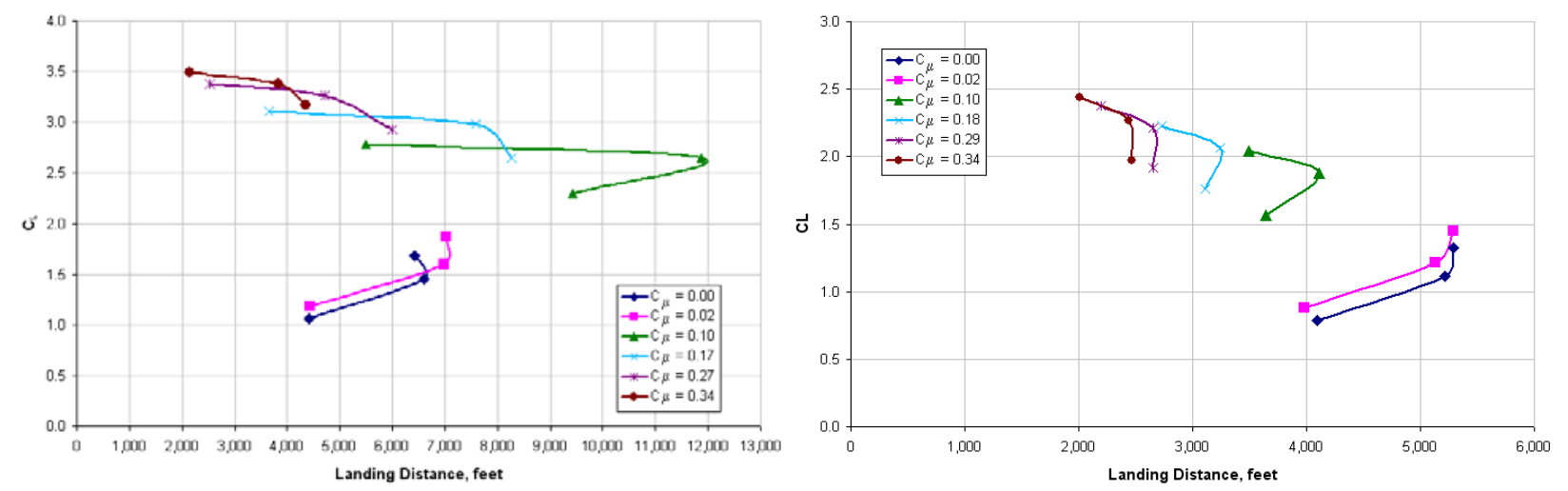

Figure 32. Landing Distance for Dual Radius Flap Figure 33. Landing Distance for Dual Radius Flap Deflection Angle $=60^{\circ}$

Deflection Angle $=90^{\circ}$

\section{Conclusion}

A number of government and non-government entities, including NASA Ames Research Center, are currently exploring ways to implement Extreme Short Take-Off and Landing (ESTOL) vehicles as a means to alleviate today's airport congestion, delays and inadequate capacity issues. Circulation Control is a high-lift system discovered in 1935 and moderately researched in the 1970's and 1980's. ESTOL vehicles can use Circulation Control, as demonstrated in this paper, for the high-lift system and therefore achieve at least two of NASA mission requirements for ESTOL vehicles: a balanced field length between 2,000 and 3,000 feet, and a landing distance with the same requirement.

Circulation Control is an active flow control system designed to produce increased lift over the traditional systems currently in use. Energy is introduced into the flow field by means of a jet ejected tangentially from a slot located near the trailing edge of the airfoil. The jet flow follows the curved Coanda surface to deflect the air and therefore create improved lift. When the jet sheet velocity is greater than that of the free stream flow, the jet remains attached to the Coanda surface because of the balance between the sub-ambient pressure within the jet flow and the centrifugal force felt on the curved surface. As jet velocity increases, the stagnation point moves forward on the lower trialing edge inducing an effective camber, thereby increasing circulation around the wing and increasing lift.

ESTOL vehicles, as conceptualized, can improve current airport problems by making use of the small, unused runways, mostly for shorter flights. Airport activity has increased considerably over the last few years, and as a result, airports have become extremely congested and undergone flight delays and/or cancellations. One way to alleviate this growing problem is to utilize the runways, airport ground, and infrastructure that are already in existence at major airports, but are too small for large aircraft, all while maintaining current air traffic patterns.

In order to make ESTOL a reality, the aircraft in question needs to be capable of achieving high lift coefficients. Circulation Control technology seems an obvious advantage for high-lift capability. This study has shown runway distances much shorter than traditional aircraft. Therefore, it can be determined that the technology lends itself extremely well to ESTOL vehicles and should be able to effectively shorten runway distances on full scale or demonstrator ESTOL aircraft.

Preliminary results, intended to match data from a GTRI study ${ }^{18}$, were very promising, therefore, results using the boundary conditions and freestream conditions of interest for an ESTOL aircraft were compiled. First, the twodimensional flow was examined in order to gain a greater understanding of what occurs during the blowing for a Circulation Control cross section. As the blowing coefficient is increased, meaning more energy is ejected into the flow field, the high pressure regions are continually increasing on the lower half of the airfoil, therefore creating a larger overall lifting force.

Moving on to the three-dimensional results, lift and drag data was collected for a design space that would apply for a take-off and/or landing situation. Four flap deflection angles were analyzed for a variety of blowing coefficients and angles-of-attack. For a flap deflection angle of zero degrees, the highest lift coefficient achieved was 2.3 for a maximum blowing coefficient of 0.35 . It can be seen that increasing blowing essentially shifts a line up on the lift coefficient axis for this flap deflection, because all of the lift curve slopes are similar to each other. Interesting to note is the jump in lift between a blowing coefficient of 0.02 and 0.15 . This is due to the doubling in mass flow rate from the prior to the later blowing coefficient; this occurrence is repeated in the other three cases as well. As a companion to the lift data, a drag polar was plotted; this shows that all of the blowing coefficients follow 
the same trend. The overall trend is parabolic, but each blowing coefficient individually reveals that lift will eventually increase less appreciably while drag continues to rise.

Next the flap was deflected to a thirty degree angle from the horizontal axis. The lift data now reveals a maximum lifting coefficient of 3.3 for the same blowing coefficient of 0.35 , a $40 \%$ increase over the previous data. Now the lift curve slopes have all decreased when compared to the flap deflection angle of zero degrees, indicting a very negative zero lift angle-of-attack, if the wing does not stall before that. Also, the drag coefficient data was recorded for this flap deflection and follows the same trend as before.

Following the process from the last two sets of data, a flap deflection angle of sixty degrees was evaluated. Again, lift coefficients increase over the previous case, but not as significantly as before, only $6 \%$ increase over the thirty degree flap deflection angle, giving a maximum lift value of about 3.5. The lift curve slopes continue to decrease, but as with the maximum lift coefficient, there was not as big a change from the previous data. Accompanying this, the drag data for the sixty degree flap deflection aligns along a single parabolic shape with fewer outliers than the two previous flap angles.

Lastly, the ninety degree flap deflection angle was evaluated. The lift for this case decreases compared to that of the sixty degree case, which means there is a flap deflection angle somewhere in between sixty and ninety where lift no longer increases, but rather decreases. The maximum lift coefficient is just below 2.5 , which is almost the same as to the case where the flap deflection was zero degree. Also of interest is the drag; it decreases, but not nearly as much as the lift. The drag is comparable to the case where the flap deflection was thirty degrees.

Based on all of the lift and drag data for the four flap deflections, balanced field length (BFL) and landing distance were calculated. The BFL is defined as the total take-off distance, including the obstacle clearance, when one engine fails at the "decision speed", which is defined as the speed where the aircraft can either brake to a halt or continue the take-off in the same total distance. Using standard BFL calculations obtained from Raymer ${ }^{49}$, and making a few assumptions about the ESTOL platform, BFL was plotted against lift coefficient for each flap deflection angle. For a flap deflection of zero degrees, the BFL intuitively decreases as lift increases. The small juts of increasing BFL are attributed to the higher drag as the lift increases associated with each blowing coefficient.

Next, as the flap deflection is increased to thirty degrees, and a much more interesting phenomenon is observed. The BFL values first decrease with lift and then increase almost to the zero blowing case. This can only be attributed to the rise in drag compared to the rise in lift. When the flap is deflected at this angle, the drag becomes a larger factor and therefore adversely affects the BFL calculations revealing undesired results. The same occurs when the flap is deflected to sixty and ninety degrees, the only difference being that the minimum BFL increases in these cases when compared to the thirty degree deflection, but both have points within the desired range. Therefore, it can be concluded that the best flap deflection angle for take-off is thirty degrees with a climb-out angle of about six degrees and a blowing coefficient of 0.23 , resulting in a BFL of 2,400 feet.

Also significant, landing distance was calculated based on all of the previous lift and drag data. The first conclusion is that a flap deflection of zero degrees is not going to cut it for landing. The lift is much too high compared to the drag, therefore, no matter what blowing coefficient is applied, the landing distance is always too long. The second conclusion is that increasing the flap deflection angle to thirty degrees has little desired effect over a zero degree flap deflection. While the shortest landing distance is now roughly 400 feet shorter, it is still too long.

A more compelling plot is that of the sixty degree flap deflection. This time there is an obvious trend that can be attributed to the lift and drag at different blowing coefficients. The landing distance is increasing with lift until drag becomes large enough to cut it down. In the sixty degree case, the shortest runway distance is 2,150 feet, but only two points in the plot are even within the NASA mission requirements. Therefore, looking at the ninety degree deflection case is beneficial. These results show that the shortest runway distance decreases by only about 150 feet, which may be significant, but also that there are over half a dozen points within the mission requirements giving a hypothetical pilot more flexibility when landing, versus the sixty degree case. Finally it was concluded that a landing distance of 2,000 feet is possible with a flap deflection of 90 degrees and a blowing coefficient of 0.34 .

To summarize, three-dimensional lift coefficients were calculated and the highest value achieved was about 3.5. This data led to the calculations of BFL and landing distance. The shortest BFL was calculated to be 2,400 feet and the shortest landing distance was 2,000 feet. Both of these values are well within the mission requirements set forth by NASA Ames. Based on these results it must be concluded that Circulation Control is an extremely viable solution for high-lift and should be incorporated into future ESTOL aircraft. By incorporating this system, these aircraft will be one step closer to alleviating the airport congestion, delays, and frequent cancellations that have become so prevalent in our society in recent years. 


\section{Acknowledgments}

A portion of this work was funded by NASA Ames Research Center ESTOL Vehicle Sector through their cooperative educational effort with California Polytechnic State University, San Luis Obispo during the summer of 2005 .

\section{References}

${ }^{1}$ Englar, Robert J. Overview of Circulation Control Pneumatic Aerodynamics: Blown Force and Moment Augmentation and Modification as Applied Primarily to Fixed-Wing Aircraft. NASA/ONR Circulation Control Workshop, March 16-17, 2004, NASA/CP-2005-213509, pp. 37-99.

${ }^{2}$ Cerchie, D. et al. Some Circulation Control Experiments. 2004 NASA/ONR Circulation Control Workshop, March 16-17, 2004, NASA/CP-2005-213509, pp. 369-405.

${ }^{3}$ Rich, Paul et al. Circulation Control in NASA's Vehicle Systems. NASA/ONR Circulation Control Workshop, March 16-17, 2004, NASA/CP-2005-213509, pp. 1-35.

${ }^{4}$ Jones, Gregory S. Pneumatic Flap Performance for a 2-D Circulation Control Airfoil, Steady \& Pulsed. NASA/ONR Circulation Control Workshop, March 16-17, 2004, NASA/CP-2005-213509, pp. 845-888.

${ }^{5}$ Jones, G.S. et al. An Active Flow Circulation Controlled Flap Concept for General Aviation Aircraft Applications. AIAA Paper 2002-3157.

${ }^{6}$ Biggers, James C. Summary of Session Seven: Circulation Control Aerodynamics Research Needs. Proceedings of the Circulation-Control Workshop 1986, February 19-21, 1986, pp. 591-599.

${ }^{7}$ Nielson, Jack n., and James C. Biggers. Recent Progress in Circulation Control Aerodynamics. AIAA-87-0001.

${ }^{8}$ Joslin, Ronald D., and Gregory S. Jones. Summary: 2004 NASA/ONR Circulation Control Workshop. NASA/ONR Circulation Control Workshop, March 16-17, 2004, NASA/CP-2005-213509, pp. 1023-1053.

${ }_{9}^{9}$ Abramson, J., and E.O. Rogers. High-Speed Characteristics of Circulation Control Airfoils. AIAA-83-0265.

10 Alexander, Michael G. Trailing Edge Blowing on a Two-Dimensional Six-Percent Thick Elliptical Circulation Control Airfoil Up to Transonic Speeds. NASA/TM-2005-213545.

${ }^{11}$ Alexander, Michael G. et al. A Wind Tunnel Experiment for Trailing Edge Circulation Control on a 6\% 2-D Airfoil up to Transonic Mach Numbers. 2004 NASA/ONR Circulation Control Workshop, March 16-17, 2004, NASA/CP-2005-213509, pp.407-434.

${ }^{12}$ Englar, Robert J., and Gregory G. Huson. "Development of Advanced Circulation Control Wing High-Lift Airfoils.” Journal of Aircraft, Vol. 21, No. 7, (1984): 476-483.

${ }^{13}$ Englar, Robert J. et al. Final Report: Summary of Research: Continued Development and Application of Circulation Control Pneumatic Technology to Advanced Transport Aircraft. NASA/CR-1998-207471.

${ }^{14}$ Cagle, Christopher M., Gregory S. Jones. A Wind Tunnel Model to Explore Unsteady Circulation Control for General Aviation Applications. AIAA Paper 2002-3240.

15 Jones, Gregory S., Robert J. Englar. Advances in Pneumatic-Controlled High-Lift Systems through Pulsed Blowing. AIAA Paper 2003-3411.

${ }^{16}$ Salikuddin, M. et al. "Noise from a Circulation Control Wing with Upper Surface Blowing." Journal of Aircraft. Vol. 24, No. 1, (1987):55-64.

${ }^{17}$ Munro, Scott E. et al. Noise Reduction through Circulation Control. 2004 NASA/ONR Circulation Control Workshop, March 16-17, 2004, NASA/CP-2005-213509, pp. 497-552.

${ }^{18}$ Harvell, J.K., and M.E. Franke. "Aerodynamic Characteristics of a Circulation Control Airfoil with Two Blown Slots." Journal of Aircraft, Vol. 22, No. 9, (1985): 737-742.

${ }^{19}$ Lui, Yi et al. Numerical Simulations of the Steady and Unsteady Aerodynamic Characteristics of a Circulation Control Wing Airfoil. AIAA Paper 2001-0704.

${ }^{20}$ Baker, Warren J., and Eric G. Patterson. Simulation of Steady Circulation Control for the General Aviation Circulation Control (GACC) Wing. NASA/ONR Circulation Control Workshop, March 16-17, 2004, NASA/CP-2005-213509, pp. 791-811.

${ }^{21}$ McGowan, Gregory, and Ashok Gopalarathnam. CFD Analysis of a Circulation Control Airfoil Using FLUENT. NASA/ONR Circulation Control Workshop, March 16-17, 2004, NASA/CP-2005-213509, pp. 813-843.

${ }^{22}$ Swanson, R.C. et al. Progress towards Computational Method for Circulation Control Airfoils. AIAA Paper 2005-0089.

23 Jones, Gregory S., and Ronald D. Joslin. Introduction: 2004 NASA/ONR Circulation Control Workshop. 2004 NASA/ONR Circulation Control Workshop, March 16-17, 2004, NASA/CP-2005-213509, pp. vii-x.

${ }^{24}$ Chang, Peter A. et al. Full-Reynolds Stress Modeling of Circulation Control Airfoils. 2004 NASA/ONR Circulation Control Workshop, March 16-17, 2004, NASA/CP-2005-213509, pp. 141-166.

${ }^{25}$ Paterson, Eric G., and Warren J. Baker. RANS and Detached-Eddy Simulation of the NCCR Airfoil. 2004 NASA/ONR Circulation Control Workshop, March 16-17, 2004, NASA/CP-2005-213509, pp. 167-195.

${ }^{26}$ Viswanathan, Aroon K., and Danesh K. Tafti. Numerical Analysis of Circulation Control on a NCCR 1510-7607N Airfoil using RANS Models. 2004 NASA/ONR Circulation Control Workshop, March 16-17, 2004, NASA/CP-2005-213509, pp. 197226.

${ }^{27}$ Swanson, R.C. Aspects of Numerical Simulation of Circulation Control Airfoils. 2004 NASA/ONR Circulation Control Workshop, March 16-17, 2004, NASA/CP-2005-213509, pp. 227-273. 
${ }^{28}$ McGowan, G. et al. Role of Turbulence Modeling in Flow Prediction of Circulation Control Airfoils. 2004 NASA/ONR Circulation Control Workshop, March 16-17, 2004, NASA/CP-2005-213509, pp. 275-293.

${ }^{29}$ Lui, Yi et al. Computational Evaluation of the Steady and Pulsed Jet Effects on the Performance of a Circulation Control Wing Section. 2004 NASA/ONR Circulation Control Workshop, March 16-17, 2004, NASA/CP-2005-213509, pp.295-336

${ }^{30}$ Loth, John L. Why Have Only Two Circulation Control STOL Aircraft Been Built and Flown in Years 1974-2004. NASA/ONR Circulation Control Workshop, March 16-17, 2004, NASA/CP-2005-213509, pp. 603-640.

${ }^{31}$ Loth, J.L., and S.C. Roberts. "Flight Performance of a Circulation Controlled STOL Aircraft." Journal of Aircraft. Vol. 13, No. 3, (1976): 169-173.

${ }^{32}$ Loth, John. Advantages of Combing BLC Suction with Circulation Control High Lift Generation. (Unpublished)

${ }^{33}$ Englar, Robert J. et al. "Design of the Circulation Control Wing STOL Demonstrator Aircraft.” Journal of Aircraft. Vol. 18, No. 1, (1981): 51-58.

${ }^{34}$ Nichols, James, and Robert J. Englar. “Advanced Circulation Control Wing System for Navy STOL Aircraft.” Journal of Aircraft. Vol. 18, No. 12, (1981): 1044-1050.

${ }^{35}$ Englar, Robert J. et al. Circulation Control Technology Applied to Propulsive High Lift Systems. SAE Technical Paper Series 841497, 1984.

${ }^{36}$ Shovlin, M.D. et al. Large-Scale Static Investigation of Circulation-Control-Wing Concepts Applied to Upper-SurfaceBlowing Aircraft. January 1987. NASA/TP2684.

37 Wood, T. From Concept to Production of the Coanda Driven Exhaust Deflector for the V-22. NASA/ONR Circulation Control Workshop, March 16-17, 2004, NASA/CP-2005-213509, pp. 771-789.

38 Angle II, Gerald M. et al. Experimental and Computational Investigation into the use of the Coanda Effect on the Bell A821201 Airfoil. NASA/ONR Circulation Control Workshop, March 16-17, 2004, NASA/CP-2005-213509, pp. 889-910

${ }^{39}$ Zha, Ge-Cheng, and Craig Paxton. A Novel Airfoil Circulation Augment Flow Control Method Using Co-Flow Jet. 2004 NASA/ONR Circulation Control Workshop, March 16-17, 2004, NASA/CP-2005-213509, pp. 469-495.

${ }^{40}$ Moore, Mark D. Wake Vortex Wingtip-Turbine Powered Circulation Control High lift System. NASA/ONR Circulation Control Workshop, March 16-17, 2004, NASA/CP-2005-213509, pp. 641-656.

${ }^{41}$ Kondor, Shayne A., and Mark Moore. Experimental Investigation of a Morphing Nacelle Ducted Fan. 2004 NASA/ONR Circulation Control Workshop, March 16-17, 2004, NASA/CP-2005-213509, pp. 435-468.

${ }^{42}$ Frith, Steven P., and Norman J. Wood. The Use of Circulation Control for Flight Control. NASA/ONR Circulation Control Workshop, March 16-17, 2004, NASA/CP-2005-213509, pp. 657-688.

${ }^{43}$ Englar, Robert J. The Application of Pneumatic Aerodynamic Technology to Improve Performance and Control of Advanced Automotive Vehicles. NASA/ONR Circulation Control Workshop, March 16-17, 2004, NASA/CP-2005-213509, pp. 957-995.

${ }^{44}$ Sahu, Dr. Jubaraj. Time-Accurate Simulations of Synthetic Jet-Based Flow Control for a Spinning Axisymmetric Body. NASA/ONR Circulation Control Workshop, March 16-17, 2004, NASA/CP-2005-213509, pp. 689-721.

${ }^{45}$ Day, Terence R. Coanda Effect and Circulation Control for Non Aerodynamic Applications. NASA/ONR Circulation Control Workshop, March 16-17, 2004, NASA/CP-2005-213509, pp. 921-946.

46 Joslin, Ronald D. Circulation Control: Issues for Naval Applications. NASA/ONR Circulation Control Workshop, March 1617, 2004, NASA/CP-2005-213509, pp. 553-575.

47 Zuk, John and Wardwell, Douglas A. Summary of NASA's Extreme Short Take-Off and Landing (ESTOL) Vehicle Sector Activities. NASA/CP-2005-013145, pp. 1-14.

${ }^{48}$ Hall, Dave et. al. Summer 2004 CalPoly/NASA ESTOL Work Presented to NASA/Ames ESTOL Vehicle Systems Sector. PowerPoint Presentation. August 27, 2004.

49 Raymer, Daniel P. Aircraft Design: A Conceptual Approach. Third Edition. Reston, VA: AIAA, 1999.

${ }^{50}$ Brandt, Steven A. et. al. Introduction to Aeronautics: A Design Perspective. Reston, VA: AIAA, 1997.

${ }^{51}$ McGowan, Gregory. et. al. A Three-Dimensional Computational Study of a Circulation Control Wing. AIAA Paper 2006-3677.

${ }^{52}$ FLUENT 6.2 User's Guide. Fluent Inc. http://www.fluentusers.com/fluent/doc/ori/html/ug/main_pre.htm 